\title{
Effects of Fuel Contamination to Marine Lubricant on Friction Behaviors between Piston Ring and Cylinder Liner
}

\author{
Z. Aydin, Ö. Savaş*, A. Parlak, İ. Keskin And K. ÜnlügençOĞLu \\ Yildiz Technical University, Naval Architecture and Maritime Faculty, Marine Engineering Department, \\ 34349, Beşiktaş, İstanbul

\begin{abstract}
In internal combustion engines, friction losses caused by piston ring and cylinder liner pair account for approximately $20 \%$ of total mechanical friction losses as reported in literature. A reduction in friction between piston ring and cylinder liner pair would therefore result in higher efficiency, lower fuel consumption and reduced emissions. In this study, the effects of different types of fuel which is contaminated to cylinder oil have been tested for investigating the friction behavior between piston ring and cylinder liners pair by a reciprocating tester depending on the load, revolution and temperature. The results showed that lubricant type and revolution have been found significant on friction behavior.
\end{abstract}

DOI: 10.12693/APhysPolA.129.617

PACS/topics: 81.40.Pq, 81.05.Bx

\section{Introduction}

Diesel engines are widely used for ship propulsion, mainly in merchant vessels due to their higher efficiency in reducing vessel fuel consumption and exhaust emissions. Nowadays, the continuously increasing costs of marine fuels in conjunction with the environmental impacts of the operation of marine diesel engines make the improvement of the engine's mechanical efficiency imperative [1].

Diesel engines manufacturers need to improve engine efficiency in different ways. Some studies aim to reduce fuel consumption by in-cylinder methods [2] or by developing new diesel combustion concepts [3]. Decreasing the friction losses is a practical way to improve fuel consumption and exhaust emissions in relation to engine efficiency. Since a significant part of the total power loss in an internal combustion engine is due to piston assembly friction, the contribution of engine piston assembly friction is important.

Diesel engines lose their energy into friction by about $4-15 \%$ of input energy. A majority of the friction losses result from the piston-cylinder liner pair which contributes to about 40 to $55 \%$ of the mechanical friction losses through the system and these numbers include the power loss from the piston, rings, and rods in roughly equal proportions [4]. For this reason, improved material or processes for the in-cylinder component of marine diesel engines have been kept to research for better friction performance [5].

The oil would not clearly stay in new condition after long-term operation, since it will get dirty with external and internal contaminants. Some of these contaminant products such as fuel will have an effect on friction behavior [5].

\footnotetext{
*corresponding author; e-mail: osavas@yildiz.edu.tr
}

Despite the fact that fuel in lubricant represents the typical condition for the ring and liner, this study has been done in this lubricating environment due to the complexity. So the goal of this study is to investigate the effects of fuels in two stroke low speed diesel engine cylinder oil on friction behavior between piston ring and cylinder liner pair under various conditions for different load, engine speed and temperature parameters. The Taguchi design method has been used for determining the optimal conditions which affects the friction behavior.

\section{Experimental \\ 2.1. Materials and methodology}

Piston ring specimens used in current study were chosen from chrome coated cast iron piston ring (84 $\mathrm{mm}$ bore), sectioned into two pieces and placed in a ring holder. To avoid misalignment, a honed cast iron cylinder liner compatible with chosen ring is used instead. 15 specimens $(15 \mathrm{~mm})$ were prepared by cutting each liner and their cut surfaces were grinded with sandpaper.

Mobilgard 570 diesel engine cylinder oil by ExxonMobil was employed as a reference lubricant for the purpose of determining effects of fuel contamination. Fuels contaminated in diesel engine cylinder oil are marine fuel oil type RMG 380 (commercial denomination: IFO 380) and marine fuel oil type DMB (commercial denomination: marine diesel oil - MDO).

A reciprocating test rig, shown in Fig. 1 was designed and manufactured to measure the coefficient of friction between piston ring and cylinder liner. Crank mechanism, giving a reciprocating motion to cylinder liner specimen is driven from a three-phase electric motor through a V-belt transmission. Weights hanged on the loading arm generate normal force as a fixed ring specimen onto the liner specimen. A Kistler 9027C three-way force sensor was inserted between the loading arm and the piston ring holder to measure friction forces and normal forces. Measuring amplifier Kistler 5073 was used. 


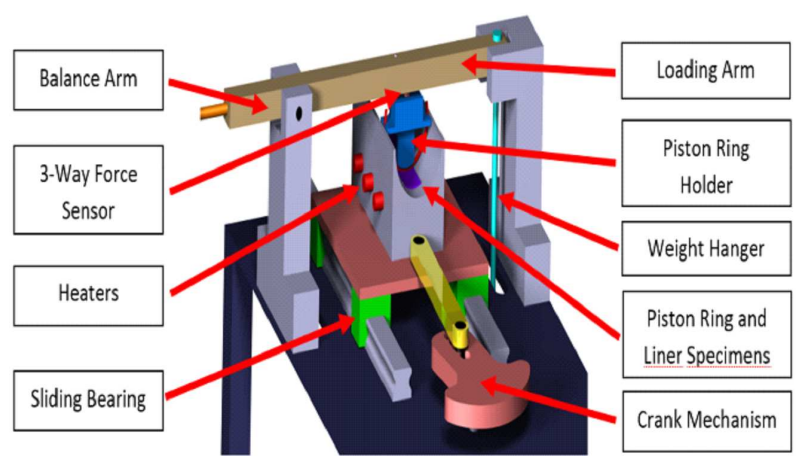

Fig. 1. Reciprocating test rig.

Temperature rise is generated by three heater cartridges (each $250 \mathrm{~W}$ ) and controlled by Eurotherm 2416 temperature control device. Oil is fed with a constant rate of $2 \mathrm{ml} / \mathrm{h}$ by capillary tube which is operated according to gravity method. In order to speed up the adjustment a frequency converter manufactured by ABB was used. Friction tests were performed with normal load and conducted at four average revolution levels. To simulate complex lubrication conditions, low speeds have been chosen in the tests as combustion pressure is the highest and the piston speed is close to zero in real diesel engine operations.

\subsection{Experimental design}

The present experiments were designed to apply the Taguchi methods to establish the effects of four parameters on the friction behavior between piston ring and cylinder liner pair. The four design parameters (factors) and their levels are given in Table I.

TABLE I

Design parameters and levels.

\begin{tabular}{|c|c|c|c|c|c|}
\hline \multirow[b]{2}{*}{ Symbol } & \multirow[b]{2}{*}{ Parameters } & \multicolumn{4}{|c|}{ Levels } \\
\hline & & 1 & 2 & 3 & 4 \\
\hline A & Lubricant type & $\begin{array}{c}\text { Pure } \\
\text { cylinder oil }\end{array}$ & $\begin{array}{c}50 \% \text { MDO } \\
\text { contamination }\end{array}$ & $\begin{array}{c}50 \% \text { IFO } 380 \\
\text { contamination }\end{array}$ & $100 \% \mathrm{MDO}$ \\
\hline B & normal load $[\mathrm{N}]$ & 60 & 80 & 100 & 120 \\
\hline $\mathrm{C}$ & speed [rpm] & 60 & 90 & 120 & 150 \\
\hline $\mathrm{D}$ & temperature $\left[{ }^{\circ} \mathrm{C}\right]$ & 60 & 80 & 100 & 150 \\
\hline
\end{tabular}

The common principle of the Taguchi method is to develop an understanding of the individual and combined effects of a variety of design parameters from a minimum number of experiments. The Taguchi method uses a generic signal-to-noise $(\mathrm{S} / \mathrm{N})$ ratio to quantify the present variation. There are several $\mathrm{S} / \mathrm{N}$ ratios available depending on the type of characteristics, including "lower is better" (LB), "nominal is best" (NB), and "higher is better" (HB).

Since the lower coefficient of friction is vital, the $\mathrm{S} / \mathrm{N}$ ratio for the $\mathrm{LB}$ characteristics is related to the present study which is given by [6]:

$$
S / N=-10 \log \left(\frac{1}{n} \sum_{i=1}^{n} y_{i}^{2}\right),
$$

where $n$ is the number of repetition in a trial under the same design conditions, $y_{i}$ represents the measured value (coefficient of friction - $\mathrm{CoF}$ ), and subscript $i$ indicates the number of design parameters in the orthogonal array (OA) which is shown in Table II.

An $L_{16}\left(4^{4}\right)$ orthogonal array table (Table III) has been employed in the design of the experiments which were carried out in the order from trial 1 to trial 18. Each trial was repeated at least three times.
Result of confirmation experiments.

TABLE II

\begin{tabular}{c|c|c|c|c}
\hline \hline \multirow{2}{*}{ Level } & \multicolumn{2}{|c|}{ Prediction } & \multicolumn{2}{c}{ Experimental } \\
\cline { 2 - 5 } & $\mathrm{S} / \mathrm{N}$ & $\mathrm{CoF}$ & $\mathrm{S} / \mathrm{N}$ & $\mathrm{CoF}$ \\
\hline $\mathrm{A}_{1} \mathrm{~B}_{1} \mathrm{C}_{4} \mathrm{D}_{1}$ & $4.95<\mu<5.36$ & $\begin{array}{c}0.00201<\mu \\
<0.00336\end{array}$ & 5.015 & 0.00311
\end{tabular}

\section{Results and discussion}

The measured coefficient of friction and their $\mathrm{S} / \mathrm{N}$ ratio values are given in Table III. As it might be seen from the table, the coefficient of friction varied between 0.0212 and 1.0269. Table IV shows that lowest coefficient of friction was obtained from trial 13 which was associated with $100 \% \mathrm{MDO}, 60 \mathrm{~N}, 150 \mathrm{rpm}$, and $60^{\circ} \mathrm{C}$. On the other hand, the highest value obtained from trial 14 was associated with $100 \% \mathrm{MDO}, 80 \mathrm{~N}, 120 \mathrm{rpm}$, and $150^{\circ} \mathrm{C}$.

Table IV shows the analysis of variance (ANOVA) for the coefficient of friction ( $\mathrm{CoF})$. According to the ANOVA table, all factors are significant at least $99 \%$ confidence. Contributions of lubricant type (A), load (B), speed (C) and temperature (D) on $\mathrm{CoF}$ were found as $33 \%, 22 \%, 30 \%$ and $14 \%$, respectively. It was shown that lubricant type $(\mathrm{A})$ and temperature $(\mathrm{C})$ were the most effective factors on CoF. These results are in good agreement with previously reported studies [7-9]. 
TABLE III

Experimental lay out and results with calculated $\mathrm{S} / \mathrm{N}$ ratios for measured coefficient of friction.

\begin{tabular}{c|c|c|c|c|c|c}
\hline \hline No & Lubricant type & $\begin{array}{c}\text { Load } \\
{[\mathrm{N}]}\end{array}$ & $\begin{array}{c}\text { Speed } \\
{[\mathrm{rpm}]}\end{array}$ & $\begin{array}{c}\text { Temp. } \\
{\left[{ }^{\circ} \mathrm{C}\right]}\end{array}$ & CoF & $\mathrm{S} / \mathrm{N}$ \\
\hline & $\mathrm{A}$ & $\mathrm{B}$ & $\mathrm{C}$ & $\mathrm{D}$ & & \\
1 & pure cyl. oil & 60 & 60 & 150 & 0.0596 & 2.45 \\
2 & pure cyl. oil & 80 & 90 & 60 & 0.0449 & 2.70 \\
3 & pure cyl. oil & 100 & 120 & 80 & 0.0434 & 2.73 \\
4 & pure cyl. oil & 120 & 150 & 100 & 0.0175 & 3.51 \\
5 & $50 \%$ MDO cont. & 60 & 90 & 80 & 0.057 & 2.49 \\
6 & $50 \%$ MDO cont. & 80 & 60 & 100 & 0.5392 & 0.54 \\
7 & $50 \%$ MDO cont. & 100 & 150 & 150 & 0.1832 & 1.47 \\
8 & $50 \%$ MDO cont. & 120 & 120 & 60 & 0.186 & 1.46 \\
9 & $50 \%$ IFO 380 cont. & 60 & 120 & 100 & 0.0581 & 2.47 \\
10 & $50 \%$ IFO 380 cont. & 80 & 150 & 80 & 0.0364 & 2.88 \\
11 & $50 \%$ IFO 380 cont. & 100 & 60 & 60 & 0.304 & 1.03 \\
12 & $50 \%$ IFO 380 cont. & 120 & 90 & 150 & 0.7273 & 0.28 \\
13 & $100 \%$ MDO & 60 & 150 & 60 & 0.0212 & 3.35 \\
14 & $100 \%$ MDO & 80 & 120 & 150 & 1.0269 & -0.02 \\
15 & $100 \%$ MDO & 100 & 90 & 100 & 0.526 & 0.56 \\
16 & $100 \%$ MDO & 120 & 60 & 80 & 0.638 & 0.39
\end{tabular}

TABLE IV

Analysis of variance (ANOVA). Sum of squares - SS, degrees of freedom $-v$, variance $-V$.

\begin{tabular}{c|c|c|c|c|c}
\hline \hline Factors & SS & $v$ & $V$ & $F_{\text {factor }}$ & $P[\%]$ \\
\hline lubricant type (A) & 6.95 & 3 & 2.32 & 242.79 & 33 \\
load* (B) & 4.56 & 3 & 1.52 & 159.35 & 22 \\
speed (C) & 6.37 & 3 & 2.12 & 222.56 & 30 \\
temperature* (D) & 3.13 & 3 & 1.04 & 109.25 & 14 \\
total & 21.01 & 12.00 & 1.75 & & \\
error & 0.03 & 3 & 0.01 & & 0.13625
\end{tabular}

Figure 2 shows $\mathrm{S} / \mathrm{N}$ response of the factors investigated on CoF. As is well known, the highest value of each factor level in the figure shows best value on CoF. The optimal combination of the factor levels are found as $\mathrm{A}_{1}, \mathrm{~B}_{1}, \mathrm{C}_{4}$ and $\mathrm{D}_{1}$ for obtaining the lowest coefficient of friction.

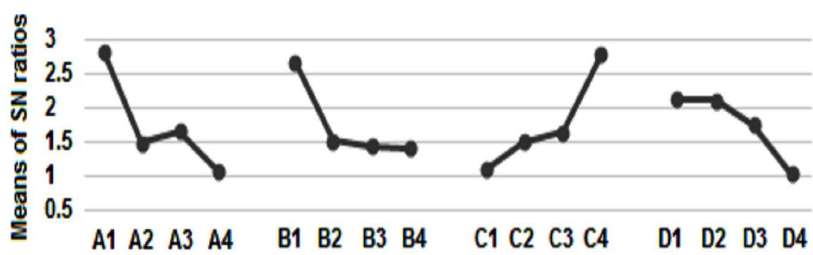

Fig. 2. Response graph for coefficient of friction.

By fuel contaminating cylinder oil, coefficient of friction has increased. 50\% IFO 380 contaminating cylinder oil caused lower coefficient of friction than $50 \% \mathrm{MDO}$ contaminating cylinder oil. Viscosity of IFO 380 fuel under the same conditions is considered to be major contributor in this result. However, maximal CoFs are obtained at low speed because the oil film thickness decreases to the level of the surfaces roughness. Maximal CoF and wear occurred during the start and near the top dead center (TDC) of engine as there is no oil film between moving parts at starting and the piston instantaneous speed reduces to zero at TDC [10].

A confirmation experiment is performed to determine the optimal conditions and to compare the results with the expected conditions following the Taguchi method. If the generated design fails to meet the specified requirement, the process must be reiterated using a new system until the required criteria are satisfied [11]. In the present work, the required confirmation experiment should satisfy the optimum design parameter (factor) combination as $\mathrm{A}_{1} \mathrm{~B}_{1} \mathrm{C}_{4} \mathrm{D}_{1}$. Since this combination of design parameter had not already been included in the main experimental layout, it is necessary to carry out an extra confirmation experiment.

Table II shows result of confirmation experiments for $\mathrm{A}_{1} \mathrm{~B}_{1} \mathrm{C}_{4} \mathrm{D}_{1}$ combination. According to the results, the average coefficient of friction was 0.00311 . The optimum condition for the coefficient of friction was estimated to lie between 0.00336 and 0.00201 . According to the result obtained from the validation trial, $\mathrm{S} / \mathrm{N}$ ratio of the coefficient of friction was 5.015, which also stays within the calculated $\mathrm{S} / \mathrm{N}$ ratio of 4.95 and 5.36 .

\section{Conclusions}

The Taguchi experimental design method has been used in present study to investigate which parameters are important in case of fuel contaminating cylinder oil during piston ring-cylinder liner pair tests.

The results of this study can be summarized as follows:

- It has been determined that lubricant type (A), load (B), speed (C) and temperature (D) are significant at least $99 \%$ confidence. Lubricant type (A), load (B), speed (C) and temperature (D) have percentage contributions of $33 \%, 32 \%, 30 \%$ and $14 \%$ to the coefficient of friction, respectively.

- Lowest coefficient of friction was obtained from the confirmation experiments which were associated with pure cylinder oil, $60 \mathrm{~N}$ load, $150 \mathrm{rpm}$, and $60^{\circ} \mathrm{C}$ temperature. By fuel contaminating cylinder oil, coefficient of friction has increased. $50 \%$ IFO 380 contaminating cylinder oil caused lower coefficient of friction than $50 \%$ MDO contaminating cylinder oil.

- In consideration of engine operating under determined load and speed conditions, temperature can be acknowledged as the most significant parameter. By increasing the temperature, viscosity decreases and $\mathrm{CoF}$ rises. Minimum $\mathrm{CoF}$ is obtained at high speed levels.

\section{Acknowledgments}

This study was supported by Yildiz Technical University (YTU) Scientific Research Project Coor. (BAPK) (project no. 2013-10-02-KAP02). Thanks to YTU BAPK for the financial support. 


\section{References}

[1] G.A. Livanos, N.P. Kyrtatos, Tribol. Int. 40, 1441 (2007).

[2] E. Arcaklioğlu, I. Çelıkten, Appl. En. 80, 11 (2005).

[3] X. Tauzia, A. Maiboom, Appl. En. 105, 116 (2013).

[4] D.E. Richardson, J. Eng. Gas Turbines Power 122, 506 (2000).

[5] J.J. Truhan, J. Qu, P.J. Blau, Tribol. Int. 38, 211 (2005).

[6] P.J. Ross, Taguchi Techniques for Quality Engineering, Loss Function, Orthogonal Experiments, Parameter and Tolerance Design, McGraw-Hill, New York 1988.
[7] W. Grabon, W. Koszela, P. Pawlus, S. Ochwat, Tribol. Int. 61, 102 (2013).

[8] S. Johansson, P.H. Nilsson, R. Ohlsson, B.-G. Rosen, Wear 271, 625 (2011).

[9] M. Kapsız, M. Durat, F. Fiçici, Adv. Eng. Software 42, 595 (2011).

[10] I. Cesur, V. Ayhan, A. Parlak, Ö. Savaş, Z. Aydin, Adv. Mech. Eng. 6, 503212 (2014).

[11] Ö. Savas, R. Kayikci, Mater. Des. 28, 2224 (2007). 